\title{
Ensino de Pensamento Computacional para alunos do ensino básico usando Computação Desplugada e Scratch
}

\author{
Teaching of Computational Thinking for elementary students using Unplugged Computation \\ and Scratch
}

\author{
Amanda Karollyne Monteiro Rodrigues ${ }^{1}$ \\ Ana Paula Mundim Silva ${ }^{2}$ \\ Murillo Guimarães Carneiro ${ }^{3}$
}

\section{RESUMO}

A tecnologia está cada vez mais presente no cotidiano das pessoas, portanto, torna- se um importante recurso no processo de ensino e aprendizagem, com possibilidade de adoção não apenas em contextos específicos de cunho tecnológico, mas também em diversas outras áreas. Mais do que isso, ela tem se consolidado como um forte instrumento de transformação social, capaz de assegurar oportunidades de reflexão, atuação e desenvolvimento em vários aspectos. O ensino do Pensamento Computacional (PC) apresenta-se como um valioso artifício no desenvolvimento de várias habilidades cognitivas cruciais para lidar com a tecnologia, tais como raciocínio lógico, criatividade, inovação, resolução de problemas de forma rápida e diversificada, entre outros. Com o objetivo de levar o PC aos estudantes do ensino fundamental de Monte Carmelo-MG, foram desenvolvidas duas oficinas sobre os conceitos da Computação Desplugada e do Scratch, as quais foram ministradas aos alunos do quinto ano do ensino fundamental de uma escola da rede pública. Como resultado, conseguimos promover um engajamento dos discentes acerca do funcionamento e da construção de tecnologias computacionais e também contribuir para uma melhoria das relações interpessoais dos envolvidos.

Palavras-chave: Pensamento Computacional. Computação Desplugada. Informática na Educação. Scratch.

\begin{abstract}
The technology is an essential educational resource in people daily live. It has been consolidated as a powerful tool for social transformation able to provide opportunities of reflection, actuation and development in several aspects of our society. Consequently, the learning of the Computational Thinking (CT) paradigm is a valuable instrument in the acquisition of several cognitive abilities to use or handle technology challenges, such as logic reasoning, creativity, innovation, problem resolution, etc. This paper aims to describe our initiative of teaching CT to students in Monte Carmelo, State of Minas Gerais, through two workshops developed on the concepts of Unplugged Computation and Scratch. To be specific, the workshops were offered to fifth grade students of a public elementary school.

\footnotetext{
${ }^{1}$ Aluna de ensino médio na Escola Estadual Professor Vicente Lopes Perez, Monte Carmelo, Minas Gerais, Brasil; bolsista de iniciação científica júnior do CNPq. (amandakarollyne884@gmail.com).

${ }^{2}$ Aluna de ensino médio na Escola Estadual Gregoriano Canedo, Monte Carmelo, Minas Gerais; bolsista de iniciação científica júnior do CNPq. (mundimanapaula315@gmail.com).

${ }^{3}$ Doutor em Ciências da Computação e Matemática Computacional pela Universidade de São Paulo, Brasil, com período sanduíche em University of Surrey, Inglaterra; professor adjunto da Faculdade de Computação da Universidade Federal de Uberlândia, Minas Gerais, Brasil; coordenador do grupo de pesquisa Artificial and Machine Intelligence in Networks (AINet). (mgcarneiro@ufu.br).
} 
As results, the initiative promoted a notable engagement of the students regarding the operation, construction, and development of computational technologies as well as contributed to improve interpersonal relationships among them.

Keywords: Computational Thinking. Unplugged Computation. Computer Education. Scratch.

\section{INTRODUÇÃO}

O mercado de trabalho tem exigido profissionais polivalentes e inovadores, o que coloca em discussão a questão de modificar-se os currículos escolares da rede pública brasileira, que carecem de projetos voltados ao domínio da tecnologia, mesmo que ela esteja intrinsecamente ligada ao cotidiano da maioria das pessoas. Entender o computador é de suma relevância para tornar possível a aplicação de seus recursos em prol do ensino e consequentemente fomentar o ambiente escolar. Dessa forma, o Pensamento Computacional (PC) auxilia no aprimoramento de habilidades cognitivas importantes, como a formulação e resolução de problemas de maneira mais fácil e rápida, organização de dados, análise de soluções, criatividade e inovação, capacidades úteis nos mais diversos âmbitos de atuação (VALENTE, 2016).

Segundo Wing (2006), o PC fundamenta-se em entender e organizar soluções para eventuais problemas, compreender sistemas e analisar o comportamento humano baseandose em lógica. No âmbito escolar, auxilia no processo de resolução de adversidades e instiga o desenvolvimento do raciocínio lógico, habilidades estimadas em diversos setores profissionais e úteis no enfrentamento de desafios ao longo da vida (WING, 2006). Entender o PC não é o mesmo que programar, no entanto, facilita a compreensão do funcionamento de um computador e aumenta a capacidade lógica. Praticamente todas as profissões necessitam de pessoas com domínio, pelo menos básico, da tecnologia, o que torna imprescindível aumentar o contato dos estudantes com o PC.

O Brasil tem passado por uma fase de progresso e muitas de suas instituições de ensino superior já contam com um setor tecnológico satisfatório. Tal situação, contudo, não se repete quando se trata do ensino básico. A infraestrutura escassa ou inexistente mostrouse um grande obstáculo na alfabetização digital de crianças e adolescentes (RODRIGUES, 2018). Pensando em formas de solucionar essa questão, surgiu a metodologia Computação Desplugada (CD), que despreza a utilização do computador no ensino de conceitos de programação, o que, por conseguinte, torna-se viável (e atrativa) sua implementação na 
realidade brasileira (RODRIGUES, 2018).

Nas últimas décadas, a CD tem reunido cada vez mais adeptos em virtude, sobretudo, de sua facilidade de implantação. Em razão de tratar-se de uma técnica que dispensa o uso de computadores, pode-se aplicá-la em contextos sociais pouco privilegiados, em que não se tem acesso a recursos tecnológicos e nem mesmo à internet (RODRIGUES, 2017). Essa metodologia visa o ensino do PC por meio de dinâmicas alegóricas e pitorescas que enfatizam a criatividade, a comunicação, o entrosamento social, o aprender fazendo e a resolução de dilemas de forma lógica (VIEIRA, 2013). Para a realização das dinâmicas, utilizam-se ferramentas de fácil aquisição, como balões, EVA, caixas de sapatos, baralhos, papel quadriculado, entre outras.

Devido ao caráter complexo da tecnologia, professores e estudantes sentem-se intimidados e desiludidos quanto a um futuro em que o PC se agregue à matriz curricular do ensino fundamental. Ponderando sobre isso, foi desenvolvida uma metodologia totalmente inédita e inusitada, a plataforma Scratch. Diferente da CD, o Scratch não dispensa o uso do computador e por isso pode representar um empecilho no ensino do PC em regiões muito pobres do país. Por outro lado, o Scratch prega o ensino dos conceitos de programação de uma forma simples e original, desprezando as linguagens tradicionais e desmistificando a crença de que é uma ciência chata e impossível de ser compreendida (RODRIGUEZ, 2015). Abusando de recursos audiovisuais e cores espalhafatosas, o Scratch visa ensinar os estudantes de uma forma divertida e que estimule a criatividade de cada aluno na criação de jogos e animações (ZAHARIJA; MLADENOVIĆ; BOLJAT, 2013). A plataforma atrai as pessoas usando seu design e gráficos chamativos, além de seu sistema de programação por meio de blocos. Os chamados blocos de comando que se juntam para a formação de um algoritmo dividem-se em nove categorias: Movimento, Aparência, Som, Caneta, Controle, Operadores, Eventos, Sensores e Variáveis. Quando comparado a linguagens de programação habituais, o Scratch se mostra de entendimento mais simplificado e produz os mesmos resultados, em aplicações básicas, de linguagens como Java e C (ZANETTI, 2017).

O presente artigo tem como objetivo geral discutir iniciativas de ensino de PC para alunos do ensino básico desenvolvidas a partir de conceitos da CD e do Scratch. Especificamente, são discutidas duas oficinas realizadas com alunos do quinto ano de uma escola pública de Monte Carmelo-MG, que buscaram, entre outros aspectos, desenvolver o raciocínio lógico dos alunos, melhorar sua noção sobre computação e programação, fortalecer a capacidade de análise crítica, promover a interação social, melhorar as habilidades de comunicação, elevar a autoestima e instigar a criatividade e a competição 
saudável entre os alunos.

O restante do trabalho está organizado da seguinte maneira: a Seção 2 apresenta uma descrição de iniciativas correlatas encontradas na literatura; a Seção 3 relata as metodologias empregadas na realização das oficinas; a Seção 4 discute os resultados obtidos nas oficinas por meio de observações das ministrantes e feedbacks dos alunos; e, por fim, a Seção 5 apresenta as considerações finais acerca do trabalho.

\section{Trabalhos relacionados}

Encontramos na literatura trabalhos relacionados ao que apresentamos neste artigo. É o caso, por exemplo, da pesquisa apresentada por Oliveira et al. (2014), que retrata o uso da computação desplugada e outras metodologias no ensino do PC. Na pesquisa é relatado que os envolvidos aguçaram seus conhecimentos computacionais e sentiram-se compelidos a continuar com os estudos.

O trabalho de Santos et al. (2016) aponta a utilização da CD como metodologia na disseminação do PC entre professores da educação infantil. O projeto foi realizado com 37 professores da rede pública e demonstrou que os envolvidos não tinham nenhum ou insignificante conhecimento acerca do PC. Apesar de interessados, os professores relataram que muito provavelmente não irão implementar as táticas aprendidas em sala de aula.

Moreira e Monteiro (2018) denotam o emprego da CD na reformulação da disciplina Estrutura de dados em uma instituição de ensino superior, visando à simplificação dos conceitos e um maior entendimento por parte dos discentes. $\mathrm{O}$ estudo apontou melhorias no aprendizado dos alunos e confirmou que é necessária a utilização de metodologias diversificadas para atrair a atenção dos estudantes e descomplicar conceitos.

Santos et al. (2015) apresentam um trabalho baseado em CD que tem como objetivo o ensino do PC por meio da formulação de algoritmos. O projeto fundamentou-se no modelo da plataforma Scratch e em uma de suas dinâmicas. Utilizando EVA, estruturou blocos de comandos que, quando encaixados, formam um algoritmo. Foram impressos em folha A4 diversos tabuleiros para a simulação dos algoritmos, além da presença de muitos itens para coletar-se. O personagem central do jogo é o Jack, representado por uma figurinha disposta no tabuleiro e o executor dos algoritmos. A pesquisa frisou o ensino das estruturas básicas de programação, como repetição e decisão.

França e Amaral (2013) desenvolveram um trabalho que teve como objetivo levar a 
alunos do ensino básico da rede pública o PC por meio de oficinas usando a plataforma Scratch. Os resultados foram bastante satisfatórios e apontam que os estudantes conseguiram aprender os conceitos propostos e empregaram o conhecimento absorvido na resolução de problemas.

O trabalho de Andrade, Silva e Oliveira (2013) propõe a utilização do Scratch no desenvolvimento de jogos digitais para auxiliarem no ensino da matemática. Como resultado, foi criado um banco de jogos com diferentes conceitos matemáticos abordados.

Zaharija, Mladenović e Boljat (2013) propõem o ensino de conceitos de programação para crianças do ensino básico para, por conseguinte, diminuir a evasão dos cursos relacionados à área da tecnologia. Softwares como Scratch e LEGO NXT-G foram considerados e, com base nas informações didáticas obtidas, foi apontada uma metodologia de ensino dividida em quatro fases, sendo trabalhados, na última, os movimentos de um "robô real".

\section{METODOLOGIA}

As oficinas "Computação Desplugada" e "Scratch" surgiram da necessidade de levar aos estudantes do ensino público brasileiro o PC, sendo fundamental na formação intelectual de crianças e adolescentes. No entanto, encontra-se totalmente negligenciado, o que torna a prática de oficinas e minicursos de caráter tecnológico imprescindível. A presente iniciativa foi realizada no ano de 2019, em parceria com uma escola pública do município Monte Carmelo-MG, e contou com 15 alunos em cada oficina, devidamente matriculados no quinto ano do ensino fundamental. As aulas foram ministradas por duas discentes, ambas estudantes do ensino médio, com experiência em programação advinda de suas participações no Programa “Jovens Programadores" (REIS et al, 2018). O projeto foi divulgado na escola e os pais dos alunos receberam um termo de participação em que foram esclarecidos sobre as oficinas e autorizaram a participação de seus filhos. Apenas aqueles estudantes cujos pais devolveram o termo assinado participaram do sorteio das vagas.

\section{Computação Desplugada}

A oficina foi empregada no próprio ambiente escolar em uma sala nos fundos da 
escola cedida pela direção e teve como metodologia a $\mathrm{CD}$, oferecendo aos alunos uma forma diferente e divertida de ensino. Por meio de dinâmicas metafóricas e lúdicas, ensinamos os principais conceitos de programação aos discentes. A oficina contou com seis aulas distribuídas ao longo de duas semanas com duração de 1h30min. Os integrantes das oficinas foram separados em três grupos (Azul, Vermelho e Preto) de cinco estudantes cada e foram instigados a competirem de forma saudável entre si e exercitarem o trabalho em equipe. Ao final de cada aula, um representante escolhido por sua equipe explicava de forma sucinta qual foi o entendimento geral que os colegas da equipe tiveram do conteúdo exposto. Cada atividade tinha uma pontuação e o grupo que conseguiu o maior número de pontos foi o vencedor. Todas as equipes receberam prêmios pela participação.

As dinâmicas empregadas contemplaram uma série de atividades baseadas em Tangram, roda de canções, cartas, decodificação binária, desenho, fotografia e trilha, as quais propiciaram o ensino dos conceitos de algoritmo, variável, condição, repetição e depuração. Especificamente na primeira aula, os alunos puderam perceber a relevância da programação através de um olhar atento para várias aplicações dela na nossa sociedade. $\mathrm{Na}$ segunda aula, trabalhamos os conceitos de algoritmo a partir de uma atividade baseada em Tangram e de variável a partir de uma atividade lúdica, considerando a disposição de objetos (valores) em caixas (memória). Na terceira aula, usamos cartas do jogo UNO e conceitos de números binários para ensinar estruturas condicionais em programação. Os conceitos de repetição e contagem foram ensinados na quarta aula, apoiados na percepção dos refrões de canções conhecidas. Na quinta aula, os alunos aprenderam o conceito de depuração a partir da análise e correção de palavras com erros ortográficos ou de atividades anteriores agora realizadas de maneira incorreta. Por fim, a sexta aula contemplou o desafio final e envolveu a formulação pelos próprios alunos de uma atividade abordando o conteúdo aprendido nas aulas.

\section{Scratch}

A segunda oficina foi realizada em uma sala de informática da própria escola e teve como recurso principal o Scratch, que apresentou aos discentes uma nova forma de programar. Por meio de diferentes jogos, apresentamos aos participantes os vários recursos do software e deixamos que eles usassem a criatividade para criar seus próprios projetos. A oficina dispôs de seis aulas distribuídas ao longo de duas semanas e com duração de 1h30min. Diferente da oficina de CD, nessa não houve competição e as atividades foram 
realizadas individualmente.

A primeira aula foi baseada em jogos da plataforma Programaê e seguiu o método Code.org para proporcionar aos estudantes uma noção do funcionamento da programação pela linguagem de blocos. As demais aulas abordaram conceitos fundamentais de programação, como algoritmo, variável, condição, repetição e depuração. Especificamente na segunda aula, trabalhamos a noção de algoritmo e variável por meio de um jogo de labirinto (exibido na Figura 1), em que os participantes puderam perceber a relevância de organizar cada passo e a necessidade de armazenar informações na resolução de um problema computacional. A terceira aula esteve relacionada ao conceito de condição, de modo que uma série de situações decorreu em um jogo a partir das escolhas dos participantes. Na quarta aula, por intermédio de um jogo estilo ping pong (vide Figura 1), os estudantes puderam entender o conceito de repetição e contagem. Na quinta aula, usamos uma versão com bugs do jogo do labirinto para que os alunos fizessem a depuração e correção dos erros. Durante as aulas, também apresentamos aos alunos alguns jogos desenvolvidos por nós (equipe organizadora) como exemplos para que na aula final pudessem desenvolver seu próprio jogo a partir dos conteúdos que eles mais gostaram durante a oficina.

Figura 1 - Jogo do labirinto (esquerda) e ping pong (direita) utilizados nas aulas de Scratch.
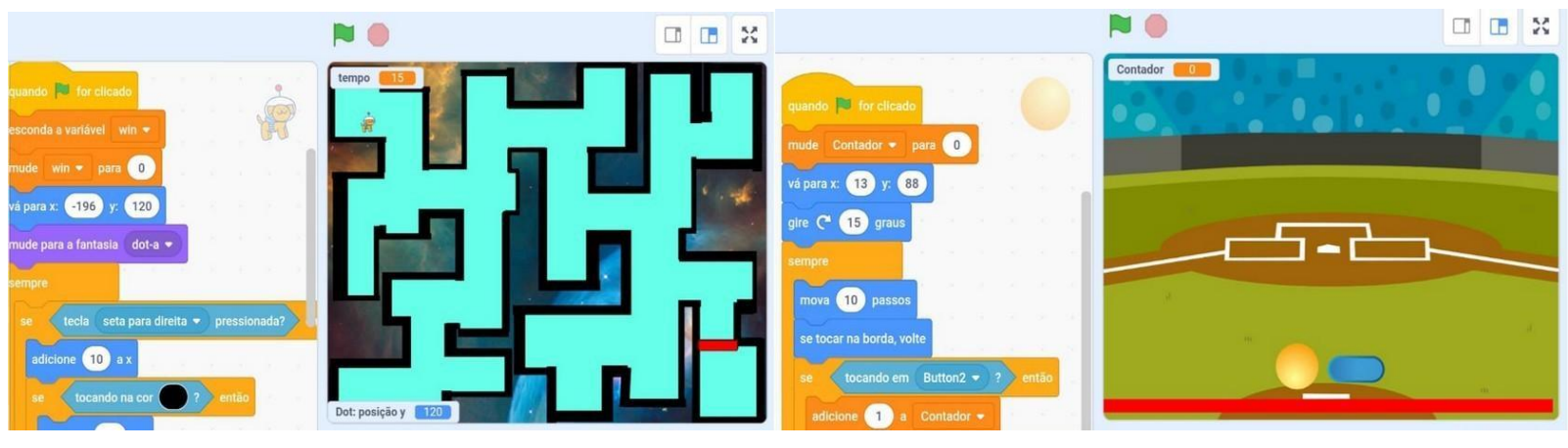

Fonte: Arquivo dos autores (2019).

\section{RESULTADOS E DISCUSSÃO}

As avaliações das oficinas foram feitas por meio de questionários disponibilizados aos estudantes pelas ministrantes e por observações feitas pela equipe organizadora das oficinas. Durante o período das aulas, notamos que houve uma maior aceitação, por parte dos alunos, em relação às atividades de $\mathrm{CD}$ do que em relação às atividades de Scratch.

$\mathrm{Na}$ oficina de $\mathrm{CD}$, os participantes se sentiram mais motivados e empolgados, além 
de terem conseguido resolver os exercícios propostos de forma relativamente fácil. A grande maioria dos estudantes conseguiu realizar todas as atividades. Na equipe vencedora houve pouco trabalho em grupo e menor interação social, enquanto a segundo colocada apresentou bom entendimento sobre o conteúdo, ótimo trabalho em equipe e interação social, porém, com deficiências em termos de organização, o que os levou a se atrapalharem com o tempo disponibilizado para a realização dos exercícios. A terceira equipe não conseguiu entregar todas as atividades, o que pode, talvez, ser explicado pela dificuldade de interação entre alguns de seus participantes.

Os alunos da oficina $\mathrm{CD}$, de forma geral, realizaram as atividades de maneira satisfatória. Na verdade, as atividades foram consideradas simples para a faixa etária dos participantes. Logo, nota-se que tal oficina, apesar de ter sido muito bem aceita pelos estudantes, não exigiu um nível elevado de esforço e comprometimento, embora tenha contribuído para propiciar um ambiente didático lúdico e participativo.

Houve algumas dificuldades durante a oficina de $\mathrm{CD}$. Os estudantes não conseguiram manter o foco e constantemente precisávamos repreendê-los por conversarem demasiadamente durante as explicações do conteúdo. Consequentemente, o tempo destinado à resolução das tarefas foi insuficiente e, inclusive, alguns estudantes expuseram seus desejos por um aumento no número de aulas da oficina. Outro problema agravante da situação foi a falta de espaço. Os grupos ficaram muito perto uns dos outros e isso pode ter contribuído para essa grande dispersão. Entretanto, mesmo com todas as ressalvas, essa oficina foi de suma importância para a comunidade e representou o primeiro contato que muitos dos participantes tiveram com conceitos tecnológicos. Houve uma melhora significativa nas habilidades sociais de alguns indivíduos e aumento de raciocínio lógico, sobretudo, devido às dinâmicas mais complexas e estratégicas.

Já a oficina de Scratch exigiu mais esforço e comprometimento dos participantes. Durante o período das aulas, notamos que os meninos conseguiram assimilar os conceitos de forma mais fácil que as meninas. Analisando o perfil dos participantes, isso se deve provavelmente ao fato de que os meninos já estavam familiarizados com a lógica da plataforma; alguns até mesmo já haviam trabalhado com o software, graças aos jogos de videogame que eles consomem diariamente. A metodologia rapidamente conseguiu a atenção dos garotos, enquanto que as garotas se dispersaram e, por conseguinte, tiveram mais dificuldade para compreender os conceitos explicados.

As atividades propostas na oficina de Scratch tiveram uma maior complexidade e abordaram de forma mais técnica o conteúdo. Devido às disparidades de progresso entre os 
estudantes, o tempo de aula foi fortemente comprometido. Os estudantes que tinham mais facilidade com a resolução dos exercícios levavam pouco tempo para solucioná-los, enquanto que os discentes com mais dificuldade precisavam de um período de tempo maior. Tal situação corroborou para que o cronograma de aulas precisasse ser alterado.

Nas aulas da oficina Scratch, enfrentamos diversos problemas, principalmente relacionados à infraestrutura. Por ser uma plataforma on-line, precisávamos de acesso à internet. Consequentemente, houve falta de computadores para todos os alunos, visto que nem todas as máquinas funcionaram de maneira adequada. Muitos alunos tiveram que fazer dupla com colegas para poder realizar as tarefas propostas, o que acarretou dispersão, sobretudo entre as meninas.

Outro grande obstáculo enfrentado durante as aulas foi o grande número de faltas apresentado por alguns estudantes. Tal fato interfere diretamente no aprendizado dos conteúdos, fazendo com que alguns discentes tivessem dificuldades para acompanhar o ritmo das aulas. Vale destacar também que muitos participantes não tinham sequer um email para realizarem o cadastro no Scratch.

Mesmo com tais empecilhos, a metodologia Scratch mostrou-se extremamente eficiente quando contornadas tais condições. A plataforma despertou o interesse de alguns alunos pela área da computação, que, mesmo após o término das oficinas, nos relataram que continuaram usufruindo dos recursos do software.

\section{Relacionamento das ministrantes com os alunos e equipe da escola}

Durante o período de aulas, nos aproximamos bastante dos estudantes e, inclusive, alguns alunos escreveram cartinhas para nos parabenizar pelo trabalho e dedicação. Ao final da oficina $\mathrm{CD}$, organizamos um piquenique em que nos divertimos muito fazendo brincadeiras e compartilhando histórias. Conversávamos bastante com os discentes e aconselhávamos aqueles que expressavam seus desejos de seguir carreira na área da Ciência da Computação. Os alunos nos contavam seus medos de ir para o colégio e nos perguntavam qual seria a melhor escola para prosseguir os estudos. Em uma das aulas, um dos participantes sofreu uma queda, o que nos deixou muito preocupadas, mas o acidente não foi grave.

Apesar de os estudantes serem muito atenciosos, às vezes eles exageravam nas conversas paralelas e não prestavam atenção às nossas explicações, mas bastava um 
simples pedido que eles rapidamente voltavam sua atenção para nós. Alguns dos participantes se propuseram a ir até o quadro da sala e explicar o que eles tinham entendido dos conceitos. Isso nos deixou muito satisfeitas, afinal, demonstrou que conseguimos estabelecer uma relação de confiança com os alunos. Ao trabalharmos as dinâmicas da oficina $\mathrm{CD}$ percebemos que uma boa parte dos estudantes conseguiu resolver os exercícios de forma fácil.

A equipe da escola também foi muito atenciosa e nos auxiliou em tudo o que precisamos. Quando fomos conversar com a diretora da escola acerca do funcionamento da oficina, ela foi muito prestativa e nos auxiliou em todo o processo. De forma geral, nosso relacionamento com os estudantes e com a equipe da escola foi muito bom e desejamos continuar com nossa parceria em trabalhos futuros.

\section{Relacionamento das bolsistas com o professor orientador}

Já conhecíamos o orientador da época em que fizemos parte de um de seus outros projetos, o "Jovens Programadores". Dessa forma, desde o princípio foi estabelecida uma relação de confiança mútua no trabalho. Não nos sentimos pressionadas pelo projeto, na verdade, é muito divertido participar do time. O professor nos auxilia em absolutamente tudo, está sempre nos mandando material para estudo, nos ajudando na formulação das oficinas e até mesmo explicando conceitos antes desconhecidos por nós. Por meio do contato com o professor, nos sentimos mais impelidas e motivadas a conhecer mais sobre a área da tecnologia. Ele nos apoia e é super compreensivo quando não podemos comparecer a uma reunião, tendo em vista o fato de sermos vestibulandas e termos muitas coisas com as quais lidar. Nossas conversas são muito interessantes e estamos sempre descobrindo coisas novas. Sentimo-nos honradas em compor a equipe e esperamos poder trabalhar juntos em outros projetos.

\section{CONSIDERAÇÕES FINAIS}

As oficinas “Computação Desplugada" e "Scratch" foram utilizadas para levar o PC a crianças do ensino público em Monte Carmelo-MG. Muitas dessas crianças tiveram seu primeiro contato com projetos relacionados à tecnologia por meio das oficinas. As metodologias usadas mostraram-se eficazes e despertaram o interesse dos estudantes, 
embora, ainda seja necessária uma lapidação. Sem cobranças demasiadas em relação aos alunos, o único intuito das oficinas foi ensinar conceitos de programação de uma forma lúdica e divertida, além de desmistificar a ideia de que o computador é complexo e impossível de ser entendido. Os projetos foram bem aceitos pela comunidade. O objetivo central de promover um engajamento dos estudantes com a tecnologia foi alcançado, além de promover uma significativa melhora das capacidades cognitivas dos envolvidos, despertar um instinto de equipe, elevar a autoestima e incitar um interesse pela computação.

Nesse sentido, os próximos passos desse trabalho consistem em aperfeiçoar as dinâmicas trabalhadas na oficina de CD, explorar ainda mais os recursos do Scratch, aumentar o tempo de aula para que todos os conteúdos possam ser transmitidos de forma calma e esmerada, providenciar a infraestrutura necessária para a realização da oficina Scratch, trabalhar na estruturação de um ambiente mais aberto e despojado, trabalhar em métodos eficientes para capturar a atenção dos estudantes, buscar formas de igualar o progresso dos alunos e promover uma maior assistência àqueles que apresentarem um índice de dificuldade muito grande.

\section{REFERÊNCIAS}

ANDRADE, M.; SILVA, C.; OLIVEIRA, T. Desenvolvendo games e aprendendo matemática utilizando o Scratch. In: SIMPÓSIO BRASILEIRO DE JOGOS E ENTRETENIMENTO DIGITAL, 12., São Paulo, 2013. Proceedings [...]. São Paulo: Mackenzie, 2013. p. 260-263, 2013. Disponível em: http://www.sbgames.org/sbgames2013/proceedings/cultura/Culture-5_short.pdf. Acesso em: 10 maio 2021.

FRANÇA, R. S.; AMARAL, H. J. C. Proposta metodológica de ensino e avaliação para o desenvolvimento do pensamento computacional com o uso do Scratch. In: WORKSHOP DE INFORMÁTICA NA ESCOLA, Porto Alegre, 2013. Anais [...]. Bento Gonçalves: SBC, 2013. Doi: 10.5753/cbie.wie.2013.179. Disponível em: https://brie.org/pub/index.php/wie/article/view/2646. Acesso em: 15 maio 2021.

MOREIRA, J. A.; MONTEIRO, W. M. O uso da computação desplugada em um contexto de gamificação para o ensino de estrutura de dados. RENOTE, Porto Alegre, v. 16, n. 2, p. 546-555, 2018. Doi: 10.22456/1679-1916.89272. Disponível em: https://seer.ufrgs.br/renote/article/view/89272. Acesso em: 15 maio 2021.

OLIVEIRA, M. et al. Ensino de lógica de programação no ensino fundamental utilizando o Scratch: um relato de experiência. In: WORKSHOP SOBRE EDUCAÇÃO EM COMPUTAÇÃO (WEI), 22., 2014, Brasília. Anais [...]. Porto Alegre: SBC, 2014, p. 239248. Disponível em: https://sol.sbc.org.br/index.php/wei/article/view/10978. Acesso em: 12 maio 2021. 
REIS, E. F. A. et al. Jovens Programadores: ensino de programação e robótica para alunos do ensino básico de Monte Carmelo-MG. In: WORKSHOP DE ENSINO EM PENSAMENTO COMPUTACIONAL, ALGORITMOS E PROGRAMAÇÃO, 2018, Fortaleza, 2018. Anais [...]. Bento Gonçalves: SBC, 2018. p. 649-658.

Doi: http://dx.doi.org/10.5753/cbie.wcbie.2018.649. Disponível em: https://brie.org/pub/index.php/wcbie/article/view/8287. Acesos em: 15 maio 2021.

RODRIGUES, S.; ARANHA, E.; SILVA, T. R. Computação desplugada no ensino de programação: uma revisão sistemática da literatura. In: BRAZILIAN SYMPOSIUM ON COMPUTERS IN EDUCATION (SIMPÓSIO BRASILEIRO DE INFORMÁTICA NA EDUCAÇÃO-SBIE), Porto Alegre, 2018. Anais [...]. Bento Gonçalves: SBC, 2018. Doi: 10.5753/cbie.sbie.2018.417. Disponível em: https://www.brie.org/pub/index.php/sbie/article/view/7998. Acesso em:

\section{RODRIGUES, S. S. Computação desplugada no ensino fundamental I: uma} experiência metodológica numa escola pública na Paraíba. 2017. 45 f. Trabalho de Conclusão de Curso (Licenciatura em Computação à Distância) - Universidade Federal da Paraíba (UFPB), João Pessoa, 2017. Disponível em: https://repositorio.ufpb.br/jspui/handle/123456789/15755?locale=pt_BR. Acesso em: 5 maio 2021.

RODRIGUEZ, C. et al. Pensamento computacional: transformando ideias em jogos digitais usando o Scratch. In: WORKSHOP DE INFORMÁTICA NA ESCOLA, Porto Alegre, 2015. Anais [...]. Bento Gonçalves: SBC, 2015. Doi: 10.5753/cbie.wie.2015.62. Disponível em: https://www.br-ie.org/pub/index.php/wie/article/view/4992. Acesso em:

SANTOS, E. R. et al. Estímulo ao pensamento computacional a partir da computação desplugada: uma proposta para educação infantil. RELATEC, Extremadura, v. 15, n. 3, 2016. Doi: 10.17398/1695-288X.15.3.99. Disponível em:

https://relatec.unex.es/article/view/2584. Acesso em: 10 fev. 2021.

SANTOS, G. et al. Proposta de atividade para o quinto ano do ensino fundamental: algoritmos desplugados. In: WORKSHOP DE INFORMÁTICA NA ESCOLA, Porto Alegre, 2015. Anais [...]. Bento Gonçalves: SBC Doi: 10.5753/cbie.wie.2015.246. Disponível em: https://www.br-ie.org/pub/index.php/wie/article/view/5030. Acesso em: 5 maio 2021.

VALENTE, J. A. Integração do pensamento computacional no currículo da educação básica: diferentes estratégias usadas e questões de formação de professores e avaliação do aluno. Revista E-curriculum, São Paulo, v. 14, n. 3, p. 864-897, 2016. Disponível em: https://revistas.pucsp.br/index.php/curriculum/article/view/29051. Acesso em: $10 \mathrm{fev}$. 2021.

VIEIRA, A.; PASSOS, O.; BARRETO, R. Um relato de experiência do uso da técnica computação desplugada. 2013. Disponível em: https://silo.tips/download/um-relato-deexperiencia-do-uso-da-tecnica-computaao-desplugada. Acesso em:

WING, J. M. Computational thinking. Communications of the ACM, New York, v. 49, n. 3, p. 33-35, 2006. Disponível em: https://cacm.acm.org/magazines/2006/3/5977computational-thinking/fulltext. Acesso em: 
ZAHARIJA, G.; MLADENOVIĆ, S.; BOLJAT, I. Introducing basic programming concepts to elementary school children. Procedia: Social and Behavioral Sciences, [s. l.], v. 106, p. 1576, 2013. DOI: 10.1016/j.sbspro.2013.12.178. Disponível em:

https://www.sciencedirect.com/science/article/pii/S1877042813048015. Acesso em:

ZANETTI, H. A. P. et al. Proposta de ensino de programação para crianças com scratch e pensamento computacional. Tecnologias, Sociedade e Conhecimento, Campinas, v. 4, n. 1, p. 43-58, 2017. Doi: 10.20396/tsc.v4i1.14484. Disponível em:

https://econtents.bc.unicamp.br/inpec/index.php/tsc/article/view/14484. Acesso em: 18 mar. 2021.

Submetido em 6 de julho de 2021.

Aprovado em 5 de agosto de 2021. 